\title{
Issues of Language and Mathematics: Contexts and Sense-Making in Word Problem-Solving
}

\author{
Percy Sepeng \\ University of South Africa \\ E-mail: sepenp@unisa.ac.za
}

Doi:10.5901/mjss.2013.v4n13p51

\begin{abstract}
The purpose of the study reported here is to explore issues of language and mathematics and to gain more understanding of the role of both home language (isiXhosa) and language of learning and teaching (LoLT) [English] when 9th grade learners engage in problem-solving and sense-making of wor (l)d problems in senior primary mathematics classrooms. The study can be viewed as a mixed method design with quantitative data informing the qualitative results. Analysis of the data generated from a test suggests that the language of both a learner and that used in a mathematical word problem tasks impact on the way the tasks are interpreted. Furthermore, the study demonstrated that the learners' problem-solving skills in English is by far adequate compared to isiXhosa during problem-solving. However, learners abilities to consider reality when solving real wor(I)d problems appeared to be marginally better in isiXhosa compared to English. Analysis of learners' interviews illustrates that, although English is the preferred LoLT, they proposed a dual-use and/or parallel-use of English and isiXhosa for teaching and learning mathematics.
\end{abstract}

Keywords: language; word problems, sense-making, problem solving, realistic considerations technique

\section{Introduction}

There is a continuing debate in South African (SA) education regarding language use for teaching and learning in multilingual classrooms (e.g., Güles, 2005; Howie, 2003, 2004). This debate centres on the language that should be used for teaching, learning, and assessment. In this country an overwhelming majority of township and rural schools officially use English as a language of teaching and learning and for assessment purposes, despite the fact that the learners in these schools often have little contact with and access to English (Taylor \& Vinjevold, 1999). The learners often have low reading, speaking and writing abilities and struggle to comprehend texts that are written in English (Mayaba, 2009).

Barkhuizen (2002) points out that English has often been stated as the language of progress, power and economic success and suggests that the African languages, despite large numbers of speakers, simply cannot compete with the status of English, a situation which challenges the aim of setting up a truly multilingual society in Africa. Constitutionally, the SA government promotes multilingualism through its Language-in-Education Policy (LiEP), which allows schools to use more than one LoLT (Setati, Adler, Reed, \& Bapoo, 2002). However, the LiEP has encountered implementation constraints and has been censured by language experts (Granville, Janks, Mphahlele, Reed, Watson, Joseph, \& Ramani, 1998), who suggest that it may not succeed in altering the prestige and power of English. Reports (see for example, Taylor \& Vinjevold, 1999; National Centre for Curriculum Research and Development [NCCRD], 2000; Setati, 2008; Mayaba, 2009) have shown that most schools are not opting for their learners' home languages as their LoLT. Consequently, there is an increase in English language instruction and a decrease in primary language instruction in SA classrooms.

The importance of language in learning is well established (Vygotsky, 1978). How language in mathematics classrooms mediates meaning making and instructional practice (Cobb, Wood, \& Yackel, 1993; Forman, 1996; Lemke, 1990; Lerman, 2001; Van Oers, 2001), as well as differential access for second language learners (Gutiérrez, 2002; Khisty, 1995; Moschkovich, 1999, 2002) has been the focus of significant research during the past few decades. Within these discussions language has been conceived in countless ways and related to the nature of mathematical talk in the classroom, the discourse practices entailed in the learning of mathematics and the challenges and opportunities of linguistically and culturally diverse mathematics classrooms.

Howie's $(2003,2004)$ analysis of the performance of SA learners in the Third International Mathematics and Science Study (TIMSS) of 1995, identified learner proficiency in English as a strong predictor of success in mathematics. 
Contrary to Howie's findings, recent reports suggest that poor performance in mathematics cannot be solely attributed to the learners' limited proficiency in English in isolation from the pedagogic issues specific to mathematics as well as the wider social, cultural and political factors that ingrain schooling (Setati, Chitera, \& Essien, 2009).

The study largely draws on the results of a research project conducted in six schools of the Eastern Cape Province of SA (Author, 2010). In particular, much of the work in this study relies both theoretically and methodologically on notions of classroom mathematics discourse and mathematical modelling in multilingual classroom settings.

\section{Literature Review}

This section looks at language and achievement in mathematics, Implications of Language in Education Policy (LiEP) on the teaching and learning of mathematics, wor(I)d problem-solving within both socio-cultural and linguistic factors, as well as teachers' and students' conceptions of real-wor(l)d problems.

\subsection{Language and achievement in mathematics}

The mathematics achievement gap between English Second Language (ESL) learners and English First Language (EFL) speakers has been well documented (Secada, 1992; Tate, 1995). Internationally and in SA, there is no long history of research into the specific mathematics schooling experiences of English second language learners. However, in the past few decades a growing number of scholars in the (mathematics) education community have suggested expanding the sphere of mathematics education research into the socio-cultural arena in order to understand the schooling and mathematics outcomes of these learners more fully (e.g., see Atweh, Forgasz, \& Nebres, 2001; Boaler, 2009; Burton, 2003). Such research originates outside the realm of 'traditional' mathematics education research and theory and supports Weissglass's (2002) assertion that the historical contexts and the socio-cultural structures in which mathematics and mathematics teaching and learning are embedded have a significant effect on students' mathematics learning and performance, especially on those students who have been historically marginalised.

In $\mathrm{SA}$, as in many previously colonised countries in Africa and Asia, there is an added level of complexity in terms of learner achievement in mathematics (Alidou \& Brock-Utne, 2005). This added level of complexity hinges on the fact that mathematics is both taught and learned in a language that is spoken at home (English) in a majority of schools in both rural and urban areas (Taylor \& Vinjevold, 1999; Fleisch, 2008).

\subsection{Implications of Language in Education Policy (LiEP) on the teaching and learning of mathematics}

It is also widely acknowledged that education policies and language-in-education policies are determined by economic interests and political ideologies (Taylor \& Vinjevold, 1999). The LiEP in SA implies that mathematics teachers and learners have to negotiate, agree, and decide which language to use, how and when to use it, in the teaching and learning of mathematics in multilingual classrooms. In previously marginalised schools of SA, mathematics teachers may prefer to use English, which is the learners' second language, but which they believe provides learners access to power, social goods and prepares them for tertiary education (Setati, 2005a).

Adler (2001) points out that the learners whose language of learning and teaching is not their home language tend to communicate in their home language when solving group mathematics tasks in multilingual classrooms. In these classroom settings, teachers have to make a decision whether to promote code-switching between the two languages with the purpose of developing meaning or just to disregard the LiEP, and continue to use English only as LoLT. Setati's (2005b) study in multilingual classrooms of SA reveals that teachers are more concerned with providing the best instruction possible that will give learners access to social class, power, higher education and employment. She argues that mathematics teachers feel guilty to code-switch as a teaching strategy because it may deprive their learners of an opportunity to acquire proficiency in English.

\subsection{Wor(I)d problem-solving: socio-cultural and linguistic factors}

A further methodological issue, which socio-cultural approaches have yet to satisfactorily address, arises from the increasingly multicultural nature of mathematics classrooms. Students' interpretations of mathematics classroom interaction relate in part to their different social, cultural and linguistic backgrounds (Author \& Webb, 2012). Analysis of classroom interaction needs to find some way of taking account of this diversity, or it risks imposing a single cultural 
perspective, that of the researcher. Discursive psychology has the potential to address some of the above-mentioned issues.

Ellerton and Clements (1991) agree that while the process children use to solve word problems are clearly a psycholinguistic concern, much research in this area has been conducted by the persons primarily interested in the cognitive processes of problem-solving, and they have not focussed on the language of the problem or of the problem solver. The overlap between 'psycholinguistic' and 'problem-solving' was the subject of comment by Rosenthal and Resnick (1974), who describe word problems in arithmetic as tasks which require the integration of linguistic and arithmetic processing skills. They argue that in word problems, a situation is described in which there is some modification, or combination of quantities.

\subsection{Teachers' and students' conceptions of real-wor(l)d problems}

This topic of real-world knowledge and realistic considerations in students' solutions of arithmetic word problems has attracted the attention of many researchers in mathematics education. Several studies (Cai \& Silver, 1995; Verschaffel, De Corte, \& Lasure, 1994) have addressed this issue by looking at students' approaches to, and solutions of nonstandard or problematic arithmetic word problems wherein the appropriate solution or mathematical model is neither obvious nor indisputable, at least if one seriously takes into account the realities of the context evoked by the problem statement.

An increasing number of researchers have consistently suggested that current school instruction given for arithmetic word problems is likely to develop in students' tendency to exclude real-world knowledge and realistic considerations from their solution processes (Cooper \& Harries, 2005; Yoshida, Verschaffel, \& De Corte, 1997; Author, 2011, Author \& Webb, 2012).

Cooper $(1994,1998)$ offers a different explanation for the reason behind the unrealistic solutions, arguing that it stems from the socio-cultural norm of schooling that emphasises de-contextualised, calculation exercises. It is further reported that students tend to give less unrealistic answers if a real wor $(I) d$ problem is presented as a social studies problem, rather than a mathematics problem (Säljö \& Wyndhamn, 1993).

\subsection{Brief theoretical framework}

The This study is framed by a socio-cultural perspective (Cooper, 1998) which proposes that collective and individual processes are directly related, and students' unrealistic responses to real world problems reflect the students' sociocultural relationship to school mathematics and their willingness to employ the approaches emphasised in school. From a socio-cultural perspective, modelling and/or problem-solving implies engaging in inter-semiotic work. In other words, one has to decide about the appropriate and useful manners of coordinating linguistic categories and mathematical expressions and operations in order to come to a solution problem (Säljö, Riesbeck, \& Wyndham, 2009). In inter-semiotic meaning-making, the truth value of statements and arguments are established on the basis of analytical considerations of how a particular usage of concepts fits into the universe of meaning that is mathematical discourse. As such the research seeks to investigate issues of language, both home and LoLT, when ninth grade English second language learners engage in problem solving and sense-making of wor(I)d problems in multilingual mathematics classrooms of marginalised township secondary schools.

\section{Research Methodology}

In this study I used a test and interviews as a strategy to collect data. Firstly, I investigated what the situation was in terms of problem-solving abilities of grade 9 second language learners. The test was also used to establish how the learners solved mathematics problems and what problems they may have mathematically. The focus group discussion provided an understanding of the learners' uses of both language of instruction and the one spoken at home.

\subsection{Design type}

The study can be viewed as a mixed-methods design with qualitative data informing quantitative information. Quantitative data were gathered via a test written in two languages re English and isiXhosa respectively. An expert in isiXhosa language and a retired professor assisted in translating the English version of a test to isiXhosa and a group of isiXhosa 
lecturers cross-checked the accuracy of translation in order to validate and quality assure the standards of the test. Learners were randomly divided into two groups in such a manner that a first half of the group wrote a test in their home language (isiXhosa) first and then immediately repeated the test in English [isiXhosa-English (IE) group]; the other half wrote the test in English and then in isiXhosa [English-isiXhosa (EI) group]. This technique was applied in order to inform us on how much effect that having already seen the test in another language has on the test scores. The assistant researcher and trained practitioners invigilated all the test sessions and were on site to clarify any emerging questions and/or problems encountered.

\subsection{Structure of the test}

The test consisted of three sections with a total of three tasks (or questions), viz. Problem-solving (PS) tasks and were presented as follow:

Solve the following three problems and write down how you arrived at the answer:

PS1: 100 children are being transported by minibuses to a summer camp at the sea-side. Each minibus can hold a maximum of 8 children. How many minibuses are needed?

PS2: Two boys, Sibusiso and Vukile, are going to help Sonwabo rake leaves on his plot of land. The plot is 1200 square meters. Sibusiso rakes 700 square meters during four hours and Vukile does 500 square meters during two hours. They get 180 rands $(R)$ for their work. How are the boys going to divide the money so that it is fair?

PS3: John's best time to run 100 meters is 17 seconds. How long will it take him to run 1 kilometre?

The three PS tasks above were coded using a schema that was an elaboration of the classification schema developed by Verschaffel, De Corte and Lasure (1994). The classification schema comprised fourteen categories, which were reduced to three general categories:

- realistic reaction (RR): comprises all cases wherein a learner either gave the (most) correct numerical solution that also took into account the real-world aspects of the problem context, as well as cases wherein there was a clear indication that the learner tried to take into account these real-world aspects, without giving the mathematically and situationally (most) accurate numerical answer.

- no reaction (NR): all those cases without any indication that the learner was aware of the realistic modelling difficulty, for example, mathematically correct but situationally inaccurate and/or incorrect or inappropriate responses, computational errors, etc. This category also provides a measure of the word problem-solving abilities of the learners.

- other reaction (OR): are all cases wherein a learner did not provide a numerical response and did not give any further written comment that indicated that the learner was aware of the realistic modelling difficulty that prevented them from answering the problem, as well as instances where learners generated incorrect responses with mathematical (or computational) errors.

\subsection{Semi-structured interviews}

The learner interviews were conducted to investigate which language they prefer to use during classroom interaction, to communicate, when they solve mathematical problems, and for assessment, and why? The results are presented below using a few selected extracts as examples from learners' responses. All questions were in English (official language of learning and teaching) and asked in the same order for all the two groups of learners consisting of eight learners per group. Learners were free to respond in their home languages, but all the learners chose to respond in English.

\subsection{Sample in this study}

The sample consisted of grade 9 learners $(n=107)$ in six township junior secondary schools. The six schools chosen were a convenience sample of a cluster of similar schools in the same district. All the schools are functional (as opposed to dysfunctional - which is the case in many instances in SA), have similar characteristics in their approach to teaching and learning contexts and are public and previously marginalized schools. The schools draw learners from low economic status. 


\title{
3.5 Material
}

In this study, the learners were given a word problem-solving (PS) task, whose solutions depended on realistic factors connected to the problem situation. The PS tasks were the modeling problem adapted from Verschaffel, Greer and Van Dooren (2009). The researchers were present throughout the problem-solving process, and learners were encouraged to write down the reasoning process they employed to arrive at and justify a particular solution.

\section{Results}

\subsection{Qualitative results}

Most of the learners indicated, from their responses, that English was a preferred language for classroom communication, when they individually talk to the teacher and present their group work to the entire classroom. This explanation was given in response to the question regarding the language that they use for communication in the classroom. Extract 1 below represents texts from the two groups of learners in different schools.

\section{Extract 1}

\author{
L(earners): $\quad$ English \\ $\mathrm{R}$ (esearcher): Why English? \\ L1: $\quad$ Because when you are educated you must know how to speak English, because maybe you will be hired in \\ a job by a white person not Xhosa speaking person and you will be required to speak English. \\ R: $\quad$ OK \\ L2: $\quad$ You must use English because when you write in mathematics book you will not write isiXhosa because it \\ is not a Xhosa period or Xhosa class, you also provide written answers in English, so it's better for you to \\ answer in English, and become used in speaking and answering in English. \\ L3: $\quad$ And English is the most used language here in South Africa. \\ R: $\quad$ Any other reason? \\ L5: $\quad$ English helps you to communicate with people from other countries, for an example the visitors for 2010 \\ soccer world cup, we will be able to communicate with them in English because they will not understand \\ isiXhosa.
}

Of many things which the texts in Extract 1 may suggest, what comes to the forefront is the learners' reasons for the use and association of "English" with "hired in a job", "the most used language here in South Africa" and "communicate with people from other countries". All these learners, in exception of learner 2, provide reasons that are not necessarily related to their classroom interactions, but those that affect their everyday-life challenges. The frequent use of the word "must" emphasizes the feeling of obligation that the learners expresses in using this language to "write in mathematics book" in order to "provide written answers in English", as stated in Extract 1 by learner 2.

Learners were also asked about the language(s) that they prefer to use when solving word problems, and the reasons for their choice. The aim of this question was to understand mathematical discourses that occur when learners solve word problems in groups and/or pairs. Data gathered from their responses to this question revealed that learners used isiXhosa to solve word problems in their groups. They primarily used their home language and then translated their solution statements into verbal and written English when they presented their solutions to the entire classroom, and in their notebooks respectively. For example, one of the learners stated that "We discuss in isiXhosa, but in the answer book we write English and we give presentation to the teacher in English". Although some of the few groups employed a parallel use of English and isiXhosa, the strategy of translating from learners' home language was consistently applied across all the groups, with learners switching between (or moving from) their home language to English.

Skiba (1997) suggests that in the circumstances where code-switching is used due to an inability of expression, it serves for continuity in speech instead of presenting interference in language. In these multilingual classrooms, codeswitching stands to be a supporting element in communication of information and in social interaction, and therefore serves for communicative purposes in the way that it is used. The notion prevails that English second language learners in these classrooms are not able to express themselves entirely in English, and allowing them to switch to their home languages is seen to compensate for such deficiency and perceived as a tool to make problem-solving a much easier process.

The data gathered from the learner interviews in this study shows that there was an unconscious switch or 
movement between isiXhosa and English. This argument is supported by the following statements made by learners when responding to the question about the difficulties that they have experienced when solving word problems in isiXhosa and/or English test, accompanied by justifications in this regard:

\section{Extract 2}

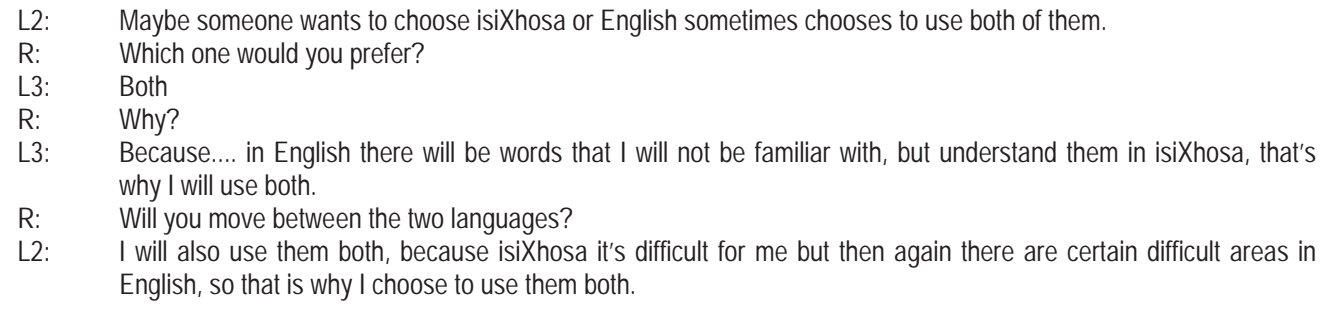

Extract 2 demonstrates that learners were granted the opportunity by their teacher to move freely between the two languages in their groups when they solve word problems. However, the switching discussed here appears to differ from the switching presented in Setati's (2005b) study, where it was indicated that both teachers and learners in multilingual classrooms code-switch freely between their utterances. In these classrooms, only learners switch freely between the languages and teachers use only LoLT for mathematics instructions.

\subsection{Quantitative results}

Table 1 depicts information generated from learners' written responses on the problem-solving (PS) items in both English and isiXhosa items. The overall percentages of realistic reactions (RRs) in the isiXhosa and English items respectively were $15 \%$ and $12 \%$, which indicate that learners' responses were more mathematically correct and situationally accurate in the isiXhosa items than the English items. As such, a more detailed look at the responses revealed that these RRs in the isiXhosa items produced more computationally correct other reactions (ORs) for PS1 and PS3, respectively, 37\%, and $55 \%$.

Table 1. Percentages (and absolute numbers) of realistic reactions (RRs), other reactions (ORs), and no reactions (NRs) on the three problem-solving (PS) English and isiXhosa items for the all groups

\begin{tabular}{lllllllll}
\hline Item & PS1 & PS2 & PS3 & Total & PS1 & PS2 & PS3 & Total \\
\hline \multicolumn{2}{l}{ English Items } & \multicolumn{6}{c}{ isiXhosa Items } \\
\cline { 2 - 9 } RR & $27 \%$ & $5 \%$ & $4 \%$ & $12 \%$ & $10 \%$ & $29 \%$ & $6 \%$ & $15 \%$ \\
& $(29)$ & $(5)$ & $(4)$ & $(38)$ & $(11)$ & $(31)$ & $(6)$ & $(48)$ \\
OR & $34 \%$ & $42 \%$ & $23 \%$ & $33 \%$ & $37 \%$ & $39 \%$ & $55 \%$ & $44 \%$ \\
& $(36)$ & $(45)$ & $(25)$ & $(106)$ & $(39)$ & $(42)$ & $(59)$ & $(140)$ \\
NR & $39 \%$ & $53 \%$ & $73 \%$ & $55 \%$ & $53 \%$ & $32 \%$ & $39 \%$ & $40 \%$ \\
& $(42)$ & $(57)$ & $(78)$ & $(38)$ & $(57)$ & $(34)$ & $(42)$ & $(48)$ \\
\hline
\end{tabular}

The Overall, the percentages of ORs on the three PS items for the isiXhosa and the English items were 44\% and 33\%, respectively. In other words, the overall quantitative results suggest that more mathematically correct responses were produced in the isiXhosa items of the pre-test compared to the English pre-tests, but these solutions were situationally inaccurate. PS3 item produced a high percentage (73\%) of no reactions (NRs) than other PS items in both sets of tests, which suggested learners' lack of awareness to succeed in realistic modeling of word problems.

\subsubsection{The effect of test order on the problem solving and sense-making}

The results of Table 2, which show the percentage of the isiXhosa-English (IE) group learners who wrote the isiXhosa items first, indicate that seeing the paper in learners' home language had no effect on achievement scores of the English items. However, $41 \%$ of the mathematically correct responses were obtained in the isiXhosa items, with $60 \%$ of these responses generated on PS3 item compared to almost a third of the ORs produced on the same item of the English 
items. So the percentage of RRs in PS2 (of the isiXhosa items) was somewhat more than that in PS1 and PS3, whereas the reverse was true for the other answers (ORs). The finding that PS2 yielded more RRs than PS1 is consistent with most previous studies showing lower percentages of realistic answers in a problem with division with a remainder (e.g., Verschaffel, 2009). This finding was not the case with responses in the English items for the IE group.

Table 2. Percentages (and absolute numbers) of (RRs), (ORs), and (NRs) on the three problem-solving (PS) items for the IsiXhosa-English (IE) group

\begin{tabular}{lllllllll}
\hline Item & PS1 & PS2 & PS3 & Total & PS1 & PS2 & PS3 & Total \\
\hline \multirow{9}{*}{ isiXhosa Items } & \multicolumn{4}{c}{ English Items } \\
\cline { 2 - 8 } RR & $13 \%$ & $36 \%$ & $5 \%$ & $18 \%$ & $35 \%$ & $7 \%$ & $5 \%$ & $16 \%$ \\
& $(7)$ & $(20)$ & $(3)$ & $(30)$ & $(19)$ & $(4)$ & $(3)$ & $(26)$ \\
OR & $33 \%$ & $31 \%$ & $60 \%$ & $41 \%$ & $30 \%$ & $49 \%$ & $25 \%$ & $35 \%$ \\
& $(18)$ & $(17)$ & $(33)$ & $(68)$ & $(17)$ & $(27)$ & $(14)$ & $(58)$ \\
NR & $55 \%$ & $33 \%$ & $35 \%$ & $41 \%$ & $35 \%$ & $44 \%$ & $69 \%$ & $49 \%$ \\
& $(30)$ & $(18)$ & $(19)$ & $(67)$ & $(19)$ & $(24)$ & $(38)$ & $(\mathbf{2 6 )}$ \\
\hline
\end{tabular}

The results of English-isiXhosa for the same three items discussed are given in Table 3. The PS1, PS2, and PS3 item elicited $40 \%, 48 \%$ and $50 \%$ ORs respectively, and an average percentage of $46 \%$ in the isiXhosa items. In fact, there was an increase of $15 \%$ ORs in the isiXhosa items after already having seen the English items. This finding indicates that learners' responses on the three items in the isiXhosa were mathematically correct after seeing the same items in English. Only 8\% of the learners produced realistic answers on the three PS tasks of the English items, compared to an increase of $4 \%$ generated for the isiXhosa items. The increase in percentage of the RRs revealed that not only more computationally correct responses were generated in the isiXhosa items, but there was also a slight improvement in the percentage of learners who succeeded in producing situationally appropriate answers after attempting the test in English first.

Table 3. Learners' Percentages (and absolute numbers) of RRs, ORs, and NRs on the three problem-solving (PS) English items for the English-IsiXhosa (El) group.

\begin{tabular}{lllllllll}
\hline Item & PS1 & PS2 & PS3 & \multicolumn{1}{c}{ Total } & PS1 & PS2 & PS3 & Total \\
\hline \multicolumn{2}{l}{ English Items } & \multicolumn{6}{c}{ isiXhosa Items } \\
\cline { 2 - 9 } RR & $19 \%$ & $2 \%$ & $2 \%$ & $\mathbf{8} \%$ & $8 \%$ & $21 \%$ & $6 \%$ & $\mathbf{1 2} \%$ \\
& $(10)$ & $(1)$ & $(1)$ & $(12)$ & $(4)$ & $(11)$ & $(3)$ & $(18)$ \\
OR & $37 \%$ & $35 \%$ & $21 \%$ & $31 \%$ & $40 \%$ & $48 \%$ & $50 \%$ & $46 \%$ \\
& $(19)$ & $(18)$ & $(11)$ & $(58)$ & $(21)$ & $(25)$ & $(26)$ & $(72)$ \\
NR & $44 \%$ & $63 \%$ & $77 \%$ & $61 \%$ & $52 \%$ & $31 \%$ & $44 \%$ & $42 \%$ \\
& $(23)$ & $(33)$ & $(40)$ & $(96)$ & $(27)$ & $(16)$ & $(23)$ & $(66)$ \\
\hline
\end{tabular}

The test results in Table 4 below depict the percentage (and absolute number) of learners who succeeded in producing three, two, one, and zero RRs to the PS tasks, illustrate that learners performed rather poorly on these items requiring not only computational skills, but realistic sense-making as well. Only $1 \%$ of learners produced three situationally accurate answers or reacted three times in a way that shows attention to the realistic modeling complexity of the problems in English items compared to 2\% in isiXhosa items. In other words, more RRs were produced in isiXhosa responses than in English.

Table 4. Percentages (and absolute numbers) of learners who produced three, two, one, and zero realistic reactions (RRs) on the problem-solving (PS) task

\begin{tabular}{lllllllllll}
\hline Category & 3 RR & 2 RR & 1 RR & 0 RR & Total & 3 RR & 2 RR & 1 RR & 0 RR & Total \\
\hline \multirow{3}{*}{ Items } & English Items & \multicolumn{7}{c}{ isiXhosa Items } \\
\cline { 2 - 10 } & $1 \%$ & $3 \%$ & $27 \%$ & $69 \%$ & $100 \%$ & $2 \%$ & $13 \%$ & $27 \%$ & $58 \%$ & $100 \%$ \\
& $(1)$ & $(3)$ & $(29)$ & $(74)$ & $(107)$ & $(2)$ & $(14)$ & $(29)$ & $(62)$ & $(107)$ \\
\hline
\end{tabular}

Statistical analysis of overall test results indicates that problem-solving of (EI) group improved by $15 \%$ in the isiXhosa 
translation after having already responded to the English test. In addition, realistic considerations of word problemsolving improved marginally by $6 \%$ (see Table 3 above) in the isiXhosa translation. In contrast, the IE group not only performed well below the El group, but their problem-solving and sense-making of word problems decreased, by $4 \%$ and $10 \%$ respectively in the English pre-test. When comparing the overall English and isiXhosa results, a negative mean $(\Delta \bar{\chi}=-2.24$ ) showed a better performance in the isiXhosa translation, and a positive mean difference score ( $\Delta \bar{\chi}=21.01$ ) suggests that learners' word problem-solving improved in English compared to the isiXhosa translation after the intervention.

\section{Discussion}

\subsection{Language of learning and teaching: English vs. isiXhosa}

Both qualitative and quantitative data analysis in this study indicate that although learners preferred both LoLT (English) and home language (isiXhosa) in mathematical word problem-solving, they performed better in English, which could be attributed to the fact that the everyday teaching of mathematics, and other subjects in general, were facilitated in English. However, learners' sense-making of word problems significantly improved in their home language. Learners' reasons for choosing English to support communication in the classroom centered around viewing English as the language of authority, power, status, prestige, and access to social goods, including jobs and international recognition, which is consistent with reports by various scholars (see Baldauf \& Kaplan, 2005; Guitierrez, 2002; Setati , 2005a; Trewby \& Fitchat, 2001). In fact, learners' use of English seemed to be aligned to these ideals, rather than as a resource or a tool to learn mathematics in the classroom. Learners' choice of LoLT is further influenced by what Adler (1998) refers to as the language of assessment.

Although all the learners seemed to be aware of the benefits of using English, some of the learners had a strong call for English to be used alongside and/or parallel to isiXhosa. This finding of the study is consistent with other reports (e.g., Setati et al., 2008) that called for pedagogical strategy that employs the use of learners' home languages deliberately and transparently (or invisibly) in order to solve real-world mathematics problems in South African classrooms. The learners who participated in this study claimed that problem-solving and connecting classroom mathematics activities to everyday-life situations is much easier to achieve, and stimulates their love for word problems when both languages are used. To some of these learners, as Hameso (2001) puts it, it seems that the use of foreign languages, such as English in education has partly made education irrelevant to the masses of their society.

Data obtained from the interviews in this study showed that learners preferred to use isiXhosa when they solve mathematical word problems in groups. This is supported by Setati and her colleagues (2008), who argue for the increased use of learners' home language, along with use of English, through dialogue and discussion in order for learners to acquire mathematical reasoning skills. It was also clear from learners' responses that learning through a medium of instruction other than the main (home) language is a challenge to both teachers and learners.

\subsection{Language use and word problem-solving}

The results of the study echo a finding by Ellerton and Clements (1991) that a major source of difficulty with mathematical word problems can be attributed to the fact that the language of mathematics and the language of common English usage often differ in important ways. Although teachers have often assumed that poor performances in word problems have arisen from lack of understanding of mathematical concepts or a deficiency in computing skills (Hate et al., 1974), the errors appeared to have been caused by an inadequate understanding of the language of the mathematics. In fact, the test results indicate that the solution errors on the problem-solving (PS) items seem to reflect deficiencies in logico-mathematical knowledge (De Corte \& Verschaffel, 1989), not akin to Cummins, Kintsch, Reusser, Weimer's (1988) reasoning fallacies.

\subsection{Test order: English-isiXhosa (EI) and isiXhosa-English (IE) groups}

The English-isiXhosa (EI) group produced more mathematically correct answers in their home language, after responding to word problems in English first. The improvement in problem-solving abilities of the El group in the isiXhosa items may possibly be attributed to the fact that English, as LoLT, as a commonly used formal written mathematical language empowered learners with clearer understanding of problems in their home language, and as such, there was a 
successful move from formal written language to informal spoken mathematical language. However, answering the isiXhosa items first resulted in the isiXhosa-English (IE) group showing a tendency to relegate reality or common-sense when solving word problems in English. This finding suggests that a decline in learners' problem-solving appeared to stem from their inability to comprehend word problems in isiXhosa items. In other words, it appeared that having seen the test in English first made it easier for the learners to comprehend and make sense of the word problems in the isiXhosa items. This finding may have implications for teacher practice, in particular assessments, in multilingual mathematics classrooms of the Eastern Cape Province where the dominant language used at home happens to be isiXhosa.

\subsection{Reality, sense-making, and context in word problem-solving}

A report by Julie and Mbekwa (2005) raises concerns with the way in which the notion of what constitutes a 'relevant context' might not be in the same for curriculum developers, teachers, and learners. In other words, the overall results of the study suggest that mathematics word problems used in school curricula are not relevant to and do not address the socio-cultural situations faced by and known to the learners from poor socio-economic backgrounds. Sethole (2004) suggests that foregrounding of context may lead to a loss of focus on the development of conceptual mathematics knowledge and render the mathematics invisible or inaccessible. Contrary to this, the results of this study suggest that with well-planned and effective teacher development interventions, the issue of context in mathematics teaching may play a pivotal role in the development of learners' problem-solving abilities.

According to a Cooper's (2008) socio-cultural perspective, modeling implies engaging in inter-semiotic work, that is, one has to decide about the appropriate and productive manners of coordinating linguistic categories and mathematical expressions and operations in order to come to a solution of a problem (Säljö et al., 2009). Learners' pretests responses indicate that strategies employed by the teachers, when teaching word problems, put more emphasis on syntax and mathematics rules rather than, what Xin (2009) refers to as, a description of some real-world situation to be modelled mathematically. As a result, it could be argued that a significant number of learners who produced the no reactions (NRs) for PS items might have made realistic considerations during the solution process of the PS items, but finally have decided to neglect these realistic considerations in their final answers. Learners may have simply anticipated that such 'unusual answers' would not be appreciated by the researcher and/or the mathematics teacher (Verschaffel et al., 2000). However, analysis of the effects of promoting discussion and use of out-of-school mathematics revealed that the ability to take into account real-world considerations properly when solving word problems increased, as expected, with sense making.

The finding that unrealistic solutions may not simply stem from mindless or procedural problem-solving, but could originate in students' diverse effort to make sense of the problem situation and the nature of the problem-solving activity in socio-cultural contexts, is consistent to the reports by Inoue (2009) and Verschaffel et al. (2009). For example, the learners' responses to the 'bus problem' (PS1 task) indicated that their everyday socio-economic life experiences and knowledge influenced the way they interpreted the problem situation (or context). In particular and as noted before, they produced different definitions of a 'week' in their problem solutions. The study has also shown that, in addition to social and cultural class inequalities that result when certain contexts are used, one group is prompted more than the other, to engage with real-world variables, thus compromising their performance (Boaler, 1994). In other words, learners who come from households of professionals, will interpret a week as having five days in cases of school teachers, or less than five days in instances where a parent is employed as a domestic worker, or any other job that requires them to report six or seven days in a calendar week. In fact, Zevenbergen's (2000) studies have shown that learners of a particular linguistic or cultural background are similarly disadvantaged or advantaged.

\section{Conclusion}

In this study the language and mathematics issues when solving real-wor(l)d problems have been investigated and reasonable conclusions drawn from both qualitative and quantitative data. The ideas generated should contribute to national and international academic debates on issues such as the realities of teaching and learning mathematics through a problem-based approach in multilingual mathematics classroom settings. In fact, the findings of this study should provide insights for individuals and groups who strive to empower mathematics teachers with innovative and effective pedagogies, particularly those who attempt to assist second language learners to use their everyday life knowledge, experiences, and common-sense understanding freely when solving mathematics word problems. 


\section{References}

Adler, J. (1998). A language of Teaching Dilemmas: Unlocking the Complex Multilingual Secondary Mathematics Classroom. For the Learning of Mathematics, 18, 24-33.

Adler, J. (2001). Teaching mathematics in multilingual classrooms. Dordrecht, Netherlands: Kluwer Academic Publishers.

Alidou H \& Brock-Utne B 2005. Teaching practices - Teaching in a familiar language. Namibia: GTZ report, 102-126.

Atweh B, Forgasz H \& Nebres B (ed.) 2001. Sociocultural research on mathematics education: An intern, ational perspective. Mahwah, $\mathrm{NJ}$ : Erlbaum.

Baldauf R \& Kaplan R 2005. Language-in-Education Policy and planning. In E Hinkel (ed.). Handbook of research in second language teaching and learning. Mahwah, NJ: Erlbaum.

Barkhuizen G P 2002. Language-in-Education Policy: students' perceptions of the status and role of Xhosa and English. In Science direct 30(4):499-515.

Boaler J 2009. Can Mathematics Problems help with the Inequalities in the World. In L Verschaffel, B Greer, W Van Dooren \& S Mukhopadhyay (eds.). Words and Worlds: Modelling verbal descriptions of situations (131:139). Netherlands: Sense Publishers.

Burton L 2003. Which way social justice in mathematics education? Westport, CT: Praeger.

Cai J \& Silver E 1995. Solution processes and interpretations of solutions in solving division-with-remainder story problems: Do Chinese and U.S. students have similar difficulties? Journal for Research in Mathematics Education, 26:491-497.

Cobb P, Wood T \& Yackel E 1993. Discourse, mathematical thinking, and classroom practice. In E Forman, N Minick \& C. Stone (Eds.). Contexts for learning: Sociocultural dynamics in children's development (91:119). Oxford, UK: Oxford University Press.

Cooper \& Harries 2000. Making sense of realistic word problems: Portraying working class "failure" in a division with a remainder problem. International Journal of Research \& Methods in Education, 22:449-463.

Cooper B 1994. Authentic testing in mathematics? The boundary between everyday and mathematical knowledge in national curriculum testing in English schools. Assessment in Education: Principles, Policy \& Practice, 11:143-166.

Cooper B 1998. Using Bernstein and Bourdie to understand children's difficulties with "realistic" mathematics testing: An exploratory study. International Journal of Quallitative studies in Education, 11:511-532.

Cummins DD, Kintsch W, Reusser K \& Weimer R 1988. The role of understanding in solving word problem. Cognitive Psychology, 20:405-438.

De Corte E \& Verschaffel L 1989. Teaching word problems in the primary school: What research has to say to the teacher. In B Greer \& G Mulhern (Eds.), New directions in mathematics education (85:107). London: Routledge.

Ellerton NF \& C1ements MA 1991. Mathematics in language: A review of language factors in mathematics learning. Geelong, Australia: Deakin University.

Fleisch B 2008. Primary education in crisis: Why South African children underachieve in reading and mathematics. Cape Town: Juta.

Forman E 1996. Learning mathematics as participation in classroom practice: Implications of sociocultural theory for educational reform. In L Steffe, P Nesher, P Cobb, G Goldin \& B Greer (eds.). Theories of mathematical learning (115:130). Mahwah, NJ: Lawrence Erlbaum Associates.

Granville S, Janks H, Mphahlele M, Reed Y, Watson P, Joseph M \& Ramani E 1998. English with or without g(u)ilt: a position paper on language in education policy for South Africa. Language and Education, 12:254-272.

Güles N 2005. The struggle for English. Johannesburg, South Africa: The Sunday Times (9 January 2005).

Gutiérrez R 2002. Enabling the Practice of Mathematics Teachers in Context: Toward A new Equity Research Agenda. In Mathematical Thinking and Learning, 4(2\&3):145 - 187.

Howie SJ 2004. A national assessment in mathematics within international comparative assessment. Perspectives in Education, 22:149-162.

Howie SJ 2003. Language and other backgrouynd factors affecting secondary pupils' performance in Mathematics in South Africa. African Journal of Research in Science, Mathematics and Technology Education, 7:1-20.

Khisty LL 1995. Making inequality: Issues of Language and Meanings in Mathematics Teaching with Hispanic students. In WG Secada, E Fennema \& LB Abajian (eds.). New Directions for equity in Mathematics Education. Cambridge: Cambridge University Press.

Lemke J 1990. Talking science: Language, learning, and values. Nordwood, NJ: Ablex.

Lerman S 2001. Cultural, Discursive Psychology: A sociocultural approach to studyng the teaching and learning of mathematics. Educational Studies in Mathematics, 46:87-113.

Mayaba N 2009. The effect of a scientific literacy strategy on grade 6 and 7 learner's general literacy skills. Port Elizabeth: Nelson Mandela Metropolitan University.

Moschkovich J 2002. A Situated and Sociocultural Perspective on Bilingual Mathematics Learners. In Journal Mathematical Thinking and Learning, 4 (2\&3):189-212.

Moschkovich J 1999. Supporting the participation of English language learners in mathematical discussions. For the learning of Mathematics, 19(1):11-19.

National Centre for Curriculum Research and Development 2000. Language in the Classroom: Towards a framework for intervention. Research Report. Pretoria: Department of Education.

Rosenthal JA \& Resnick LB 1974. Children's solution processes in arithmetic word problems. Journal of Educational Psychology, 66(6):817-825.

Säljö R \& Wyndhamn J 1993. Solving everyday problems in the formal setting: An empirical study of the school as context for thought. In 
S Chaiklin \& JLave (Eds.), Understanding practice: Perspectives on activity and context. New York: Cambridge University Press. Secada W 1992. Race, ethnicity, social class, language and achievement in mathematics. In D. Grouws (ed.). Handbook of Research on Mathematics Teaching and Learning. New York: National Council of Teachers of Mathematics.

Sepeng J.P 2010. Grade 9 second-language learners in township schools: Issues of language and mathematics when solving word problems. Unpublished doctoral dissertation. Port Elizabeth: Nelson Mandela Metropolitan University.

Sepeng J.P 2011. Triadic dialogue: An analysis of interactions in multilingual mathematics primary classrooms. US-China Education Review, 8(4): 412-418.

Sepeng J.P \& Webb P 2012. Exploring mathematical discussion in word problem-solving. Pythagoras, 33(1):1-8

Setati M 2008. Access to mathematics versus access to the language of power: the struggle in multilingual classsrooms. South African Journal of Education, 28:103-116

Setati M 2005a. Power and access in multilingual mathematics classrooms. Proceedings of the 4th international mathematics education and society conference. Australia: Centre for learning and research, Griffith University.

Setati M 2005b. Teaching mathematics in a primary multilingual classroom. Research in mathematics education, 36(5):447-466.

Setati M, Chitera N \& Essien A 2009. Research on Multilingualism in mathematics education in South Africa: 2000-2007. African Journal of Research in MST Education, Special Issue, 65-80.

Setati M, Adler J, Reed Y \& Bapoo A 2002. Incomplete Journeys: Code-switching and other language practices in mathematics, science and English language classrooms in South Africa. Language and Education, 16(2):128 - 149.

Setati M, Molefe T \& Langa M 2008. Using Language as a Transparent Resource in the Teaching and Learning of Mathematics in a Grade 11 Multilingual Classroom. Pythagoras: Journal of the Association for Mathematics Education of South Africa, 67:14-25.

Skiba R 1997. Code-switching as a Countenance of Language Interference. The internet TESL journal, vol. III, (10). Available at http://iteslj.org/. Accessed on 6th January 2009.

Tate W F 1995. School mathematics and African American students: Thinking seriously about opportunity-to-learn standards. Educational Administration Quarterly, 31:424-448.

Taylor N \& Vinjevold P 1999. Getting Learning Right: Report of the President's Education Initiative Research Project. Johannesburg, South Africa: Joint Education Trust.

Trewby R \& Fitchat S 2001. Language development in Southern Africa: Making the right choices. Windhoek, Namibia, Gamsberg: Macmillan Press.

Van Oers B 2001. Educational forms of initiation in mathematical culture. Educational Studies in Mathematics, 46:59-85.

Verschaffel L, De Corte E \& Lasure S 1994. Realistic considerations in mathematical modelling of school arithmetic word problems. Learning and Instruction, 4:273-294.

Verschaffel L, Greer B \& Van Dooren W 2009. Words and Worlds. Netherlands: Sense Publishers.

Vygotsky L 1978 . Mind in Society: The Development of Higher Psychological Processes. Cambridge, MA: Harvard University Press.

Weissglass J 2002. Inequity in mathematics education: Questions for educators. The Mathematics Educator, 12(2), 34-39.

Yoshida H, Verschaffel L \& De Corte E 1997. Realistic considerations in solving problematic word problems: Do Japanese and Belgian children have the same difficulty? Learning and Instruction, 7:329-338. 
